\title{
Slitted inset fed butterfly-shaped microstrip patch antenna
}

\author{
Mustafa Indzic ${ }^{1}$, Sehabeddin Taha İmeci ${ }^{* 2}$ \\ ${ }^{1,2}$ Department of Electrical and Electronics Engineering, International University of Sarajevo, Bosnia
}

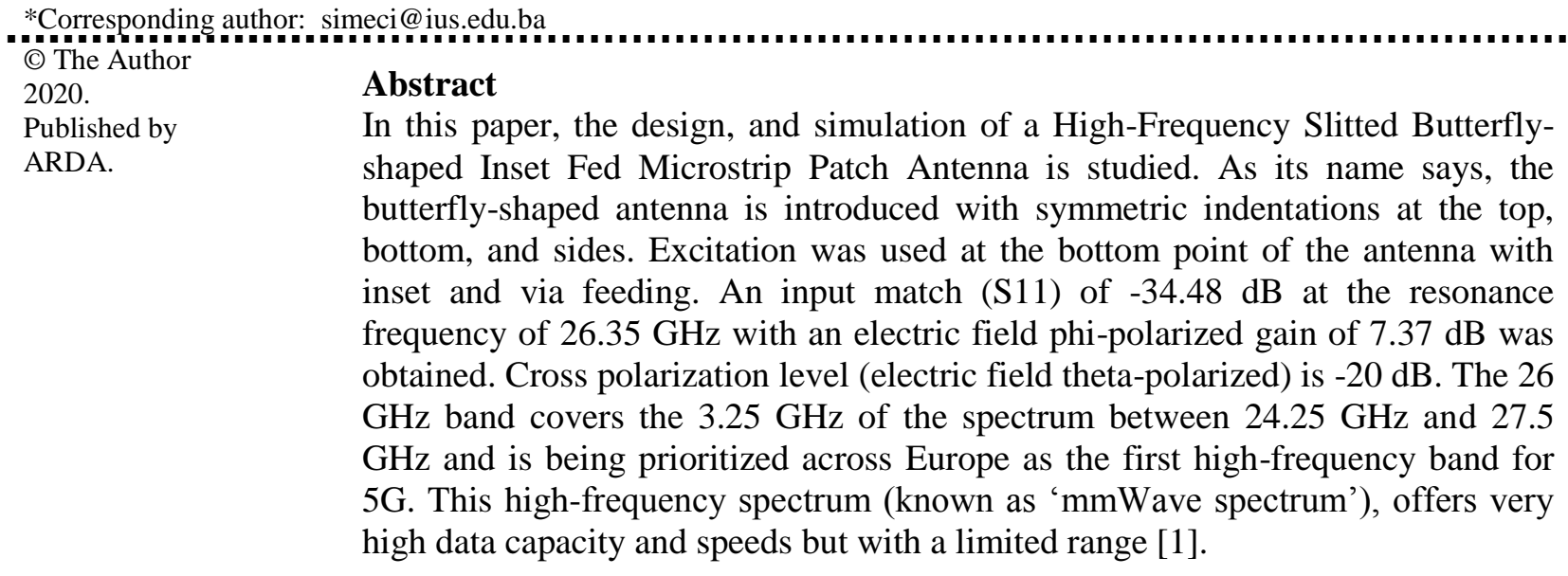

Keywords: Inset Fed, Slitted, Microstrip Patch Antenna, Butterfly

\section{Introduction}

Antenna miniaturization has been the significant issue of numerous studies for nearly seventy years. Recently, most of the cell devices industry and several academic institutions have been focusing to reduce the form factor of different types of antennas while trying to maintain satisfactory matching properties and operating bandwidth. These miniaturization techniques are related to changing the geometrical and physical properties of the antenna [2].

Broadband application performing various tasks and wireless gadgets have come out to be a fundamental part of our day by day correspondence life. Therefore, the requirement for low profile wideband has been scaled down [3]. Printed (microstrip patch) antennas are the most important types of antennas. There are several categories of the microstrip patch antennas, such as a square radiating element, triangular, semicircular, but the most common is rectangular element [4].

There are also other shapes such as perturbed square or circular patches which are used for special purposes such as to generate circular polarization with single feed, to get double resonances etc. Microstrip patch antennas are used in a broad range of applications such as satellite, missiles, cellphones, aircrafts, biomedical systems. They have several attractive properties like low profile, easy to fabricate, easy to feed, can be put in an array or incorporate with other microstrip elements, economic efficiency.

On the other hand, there are some disadvantages like narrow bandwidth which can be enhanced, efficiency is limited (conductor and dielectric losses), efficiency may be lower than other antennas, low power handling capacity, etc. [5]. Recently, high-speed wireless computer networks have attracted the attention of researchers, especially in the $5-6 \mathrm{GHz}$ band. This band can cover the frequencies of the high-speed wireless computer networks and the RFID UHF band in North America [6]. The fifth-generation network is expected to greatly

This work is licensed under a Creative Commons Attribution License (https://creativecommons.org/licenses/by/4.0/ ) that allows others to share and adapt the material for any purpose (even commercially), in any medium with an acknowledgement of the work's authorship and initial publication in this journal. 
enhance communication capacity by exploiting the vast amount of spectrum in the millimeter wave. It is also expected to be able to provide and support very high data rates as much as 100 times of fourth generation capacity [7]. Frequency ranges are given in $\mathrm{dB}$ which is the most convenient way for this design and analysis. Since this is a high frequency antenna, only frequencies above $15 \mathrm{GHz}$ are considered. Main characteristics of design are given as follows:

- Dielectric constant $\varepsilon_{r}=2.33$ (Rogers RT5870)

- Frequency range of $24.25 \mathrm{GHz}$ to $27.5 \mathrm{GHz}$

- Box size 43x43 mm

- Cell size $0.1 \times 0.1 \mathrm{~mm}$

- Antenna size $4.6 \times 3.5 \mathrm{~mm}$

\section{Design methodology}

Top view of the design with all dimensions is shown in Fig. 1, while output response and gain are shown in Fig. 2 and Fig. 3. Design and analysis are done in Sonnet software [8]. Antenna has two insets from which bottom one has grounded port, and it has two symmetrical sides which look like wings of a butterfly. The name of the design sits behind those two symmetrical sides. Since nowadays communication circuit weights a lot, many dual band circuits are created to reduce its volume, including antennas, couplers and filters [9]. Inset fed antenna offers the advantage of being planar and easily etched as well as providing adjustable input impedance through inset geometry changes [5]. Comparing this microstrip antenna with other, conventional ones, it is smaller in size and proposes new design with very good results.

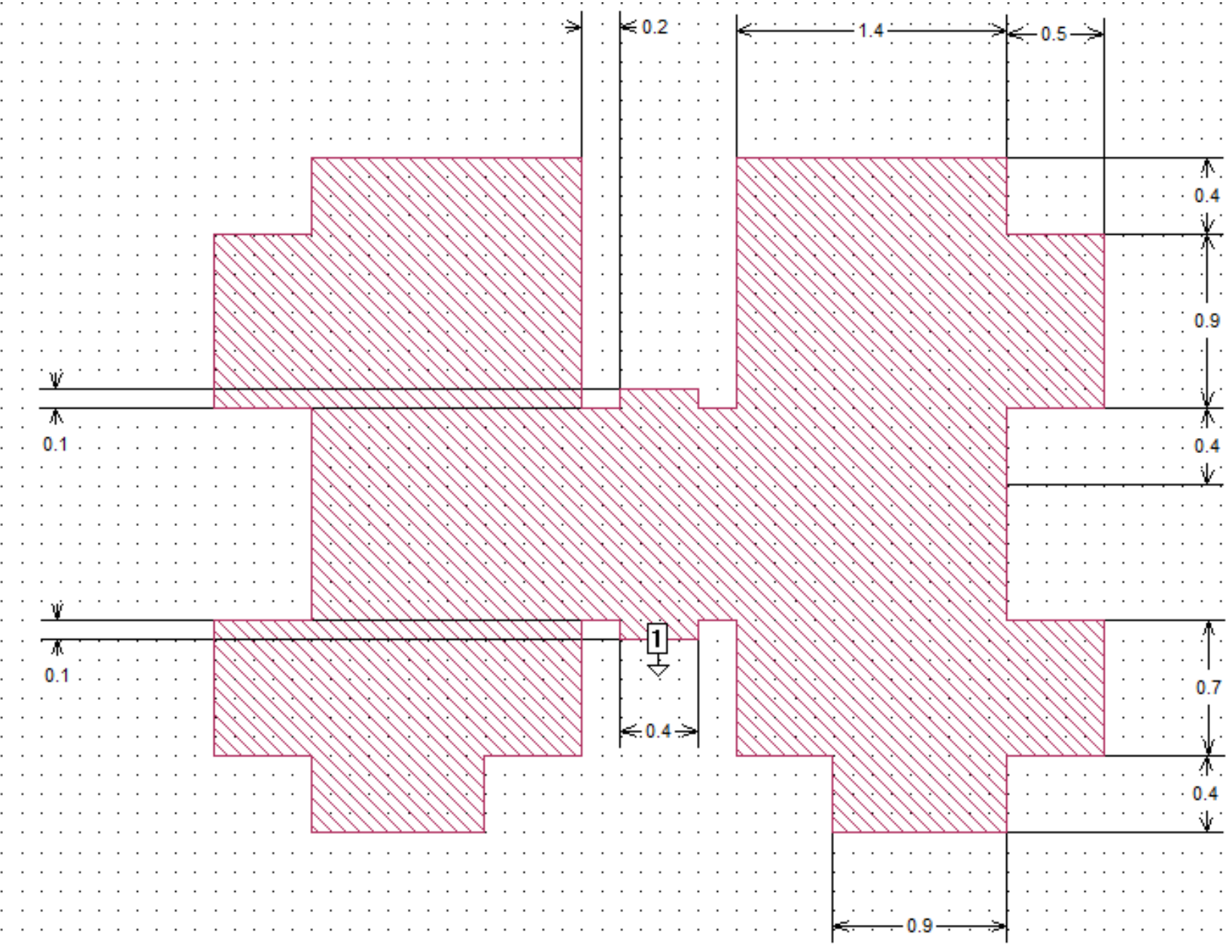

Figure 1. Design of the slitted inset fed butterfly-shaped microstrip patch antenna 


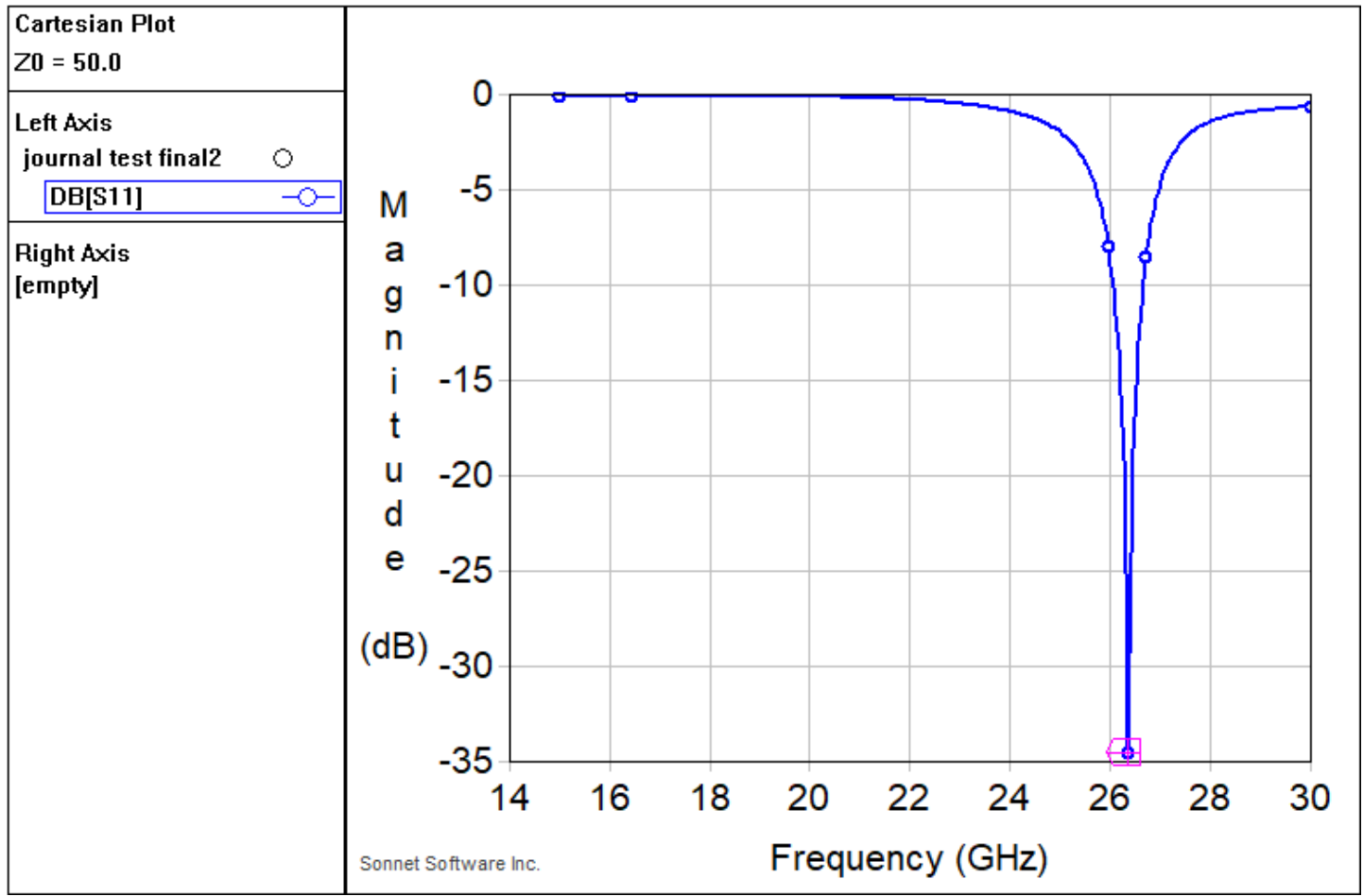

Figure 2. Output signal of the slitted inset fed butterfly-shaped microstrip patch antenna

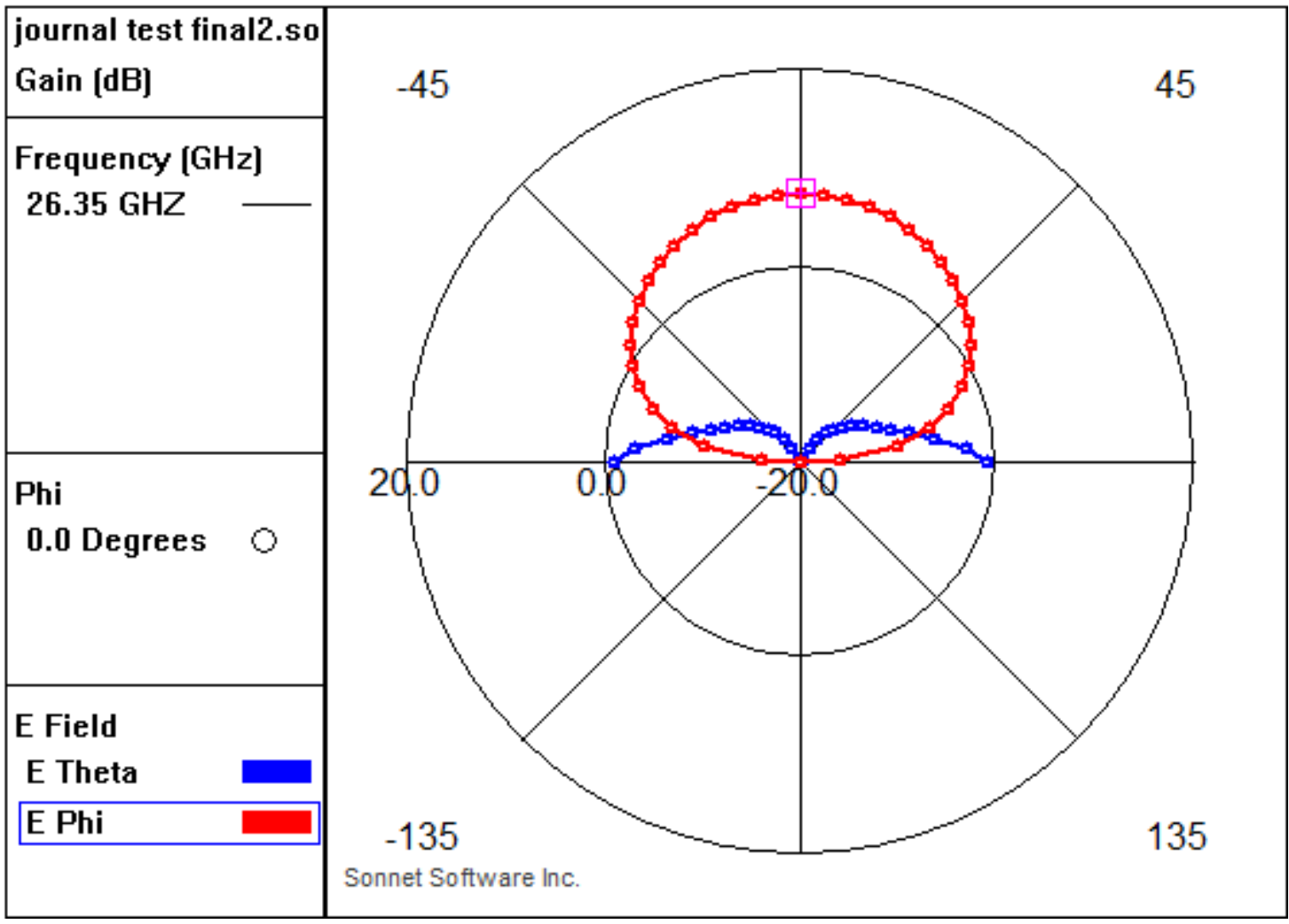

Figure 3. Gain output of the slitted inset fed butterfly-shaped microstrip patch antenna

The design of a microstrip antenna is not always an easy problem and the antenna designer is faced with difficulties coming from: a) the inherent disadvantages of a printed resonant antenna element, for example the narrow impedance bandwidth, and b) the various requirements of the specific applications, which concern the operation of the radiating element, and cannot be satisfied by a printed scheme with an ordinary configuration 
[10]. This design does not follow any of classical antenna designs specifically, but it is made to be as unique as possible, and also to have good results. In inset fed microstrip patch antenna the location of feed determines the antenna input impedance [11]. As a starting point, rectangular shaped inset fed antenna was chosen, and then some indentations were introduced, length of the inset was changed, etc. This will be explained in the following section. Millimeters were chosen as the unit of measurement because they are the most suitable in accordance with European standards and the proposed design. The material which has the dielectric constant in the range of $2.2 \leq \varepsilon_{\mathrm{r}} \leq 12$ can be used as substrate [12]. For dielectric material Rogers RT5870 with dielectric constant 2.33 is chosen since it is commonly used, easiest for fabrication and gives good performance. Similar situation is with choosing the metal type of the filter. Copper is found to be the best since it is cheapest and gives good performance. Source impedance is given as usual common value of 50 Ohms. For cell size, $0.1 \mathrm{~mm}$ is taken. It gives fast response of simulation since the box size is quite small. If it is chosen to be larger than simulations would take much more time to finish, making the antenna slower and unstable with huge deviations in output signal.

\section{Parameter variations}

As mentioned above, main studies are done examining the changes in geometry. To be able to design microstrip patch antennas to meet the performance specifications, the antenna engineer should possess a combination of certain knowledge and skills [11]. The main parameters to evaluate the performance of any antenna are:

- Input match (expressed as ratio of reflected power and power transmitted to the source)

- VSWR (Voltage Standing Wave Ratio)

- Gain

The S parameter (input match) is important concept in microwave design since it is easy to measure and indicate the results of output signal. Note that values for S parameter are given in decibels (dB). Input match represents the amount of power reflected back to the source. VSWR is comparison between the maximum voltage amplitude towards standing wave minimum voltage amplitude [14]. It is expected to get small value for the input match for better performance. Since values are expressed in decibels, the aim is to get the negative values for input match. Output of the signal is shown in Fig. 2 in the form of Cartesian plot. There it can be seen that the input match is $-34.48 \mathrm{~dB}$, while gain is shown in Fig. 3 in the polar form and the gain at $26.35 \mathrm{GHz}$ is $7.37 \mathrm{~dB}$. While analyzing the antenna, one thing that was noticed is that the length of insets pretty much dictates the output signal of the antenna. In Table 1, the effect of changing the length of top and bottom insets is observed in terms of input match and gain. Note that they are symmetrical. As it can be seen, when insets are shortest, the input match has the best result, meaning that there is almost no reflection. Tables 2 and 3 provide information about signals while changing indentations depth and dielectric thickness respectively.

Table 1. Changing the length of insets

\begin{tabular}{cccc}
\hline Inset length & Frequency & S11 & Gain \\
\hline $0.1 \mathrm{~mm}$ & $25.25 \mathrm{GHz}$ & $-36.99 \mathrm{~dB}$ & $6.75 \mathrm{~dB}$ \\
$0.3 \mathrm{~mm}$ & $25.35 \mathrm{GHz}$ & $-20.17 \mathrm{~dB}$ & $6.79 \mathrm{~dB}$ \\
$0.6 \mathrm{~mm}$ & $25.45 \mathrm{GHz}$ & $-18.40 \mathrm{~dB}$ & $6.96 \mathrm{~dB}$ \\
$1 \mathrm{~mm}$ & $25.50 \mathrm{GHz}$ & $-25.76 \mathrm{~dB}$ & $7.03 \mathrm{~dB}$ \\
$1.1 \mathrm{~mm}$ & $25.45 \mathrm{GHz}$ & $-29.85 \mathrm{~dB}$ & $6.97 \mathrm{~dB}$
\end{tabular}

As mentioned above, even small changes in geometry affect final output signal. Antennas are sensitive devices. In Table 2 indentations depth $(0.3 \mathrm{~mm}$ part from both sides, minus sign means in different direction) 
has been changing and results were observed. After this parametric study, it is chosen to remove the indentation because it has the best combination of results of input match and gain.

Table 2. Changing the indentations depth

\begin{tabular}{cccc}
\hline Indentation depth & Frequency & S11 & Gain \\
\hline $0 \mathrm{~mm}$ & $26.35 \mathrm{GHz}$ & $-34.48 \mathrm{~dB}$ & $7.37 \mathrm{~dB}$ \\
$0.3 \mathrm{~mm}$ & $25.25 \mathrm{GHz}$ & $-36.99 \mathrm{~dB}$ & $6.75 \mathrm{~dB}$ \\
$0.5 \mathrm{~mm}$ & $24.05 \mathrm{GHz}$ & $-18.27 \mathrm{~dB}$ & $6.52 \mathrm{~dB}$ \\
$-0.3 \mathrm{~mm}$ & $26.45 \mathrm{GHz}$ & $-29.71 \mathrm{~dB}$ & $7.41 \mathrm{~dB}$ \\
$-0.5 \mathrm{~mm}$ & $26.45 \mathrm{GHz}$ & $-27.37 \mathrm{~dB}$ & $7.41 \mathrm{~dB}$ \\
\hline
\end{tabular}

The material which has the dielectric constant in the range of $2.2 \leq \varepsilon$

$\mathrm{r}$

$\leq 12$ can be used as substrate

The material which has the dielectric constant in the range of $2.2 \leq \varepsilon$

$\mathrm{r}$

$\leq 12$ can be used as substrate

Referent dielectric thickness is $0.3 \mathrm{~mm}$, and air layer is 20 times bigger. Small changes were made increasing and decreasing those two. Air layer has to be at least 10 times larger. Results are shown in Table 3.

Table 3. Changing dielectric and air thicknesses

\begin{tabular}{ccccc}
\hline Dielectric thickness & Air layer thickness & Frequency & S11 & Gain \\
\hline $0.3 \mathrm{~mm}$ & $6 \mathrm{~mm}$ & $26.35 \mathrm{GHz}$ & $-34.48 \mathrm{~dB}$ & $7.37 \mathrm{~dB}$ \\
$0.3 \mathrm{~mm}$ & $3 \mathrm{~mm}$ & $26.30 \mathrm{GHz}$ & $-27.16 \mathrm{~dB}$ & $7.10 \mathrm{~dB}$ \\
$0.5 \mathrm{~mm}$ & $5 \mathrm{~mm}$ & $25.60 \mathrm{GHz}$ & $-17.15 \mathrm{~dB}$ & $6.99 \mathrm{~dB}$ \\
$0.6 \mathrm{~mm}$ & $12 \mathrm{~mm}$ & $25.10 \mathrm{GHz}$ & $-24.37 \mathrm{~dB}$ & $7.66 \mathrm{~dB}$ \\
$0.2 \mathrm{~mm}$ & $4 \mathrm{~mm}$ & $26.75 \mathrm{GHz}$ & $-27.95 \mathrm{~dB}$ & $7.06 \mathrm{~dB}$ \\
\hline
\end{tabular}

Although obtained results provide good output signal, real results may differ from it due to the dielectric loss, edge capacitance and etc. [14].

\section{Numerical analysis and equivalent circuit}

There are several analysis techniques of microstrip patch antennas:

- Transmission Line Equivalent Circuit Method

- Cavity Model (Multimode theory)

- Integral Equation (Moment Method)

- Finite Element Method (FEM)

- Finite Difference Time Domain (FDTD)

- Transmission Line Modeling (TLM).

From those above, FEM, FDTD and TLM are the most accurate, but they take more time and they cost more to implement [5]. The software that is used for analysis of this antenna, Sonnet Suites, uses Integral Equation 
(Moment Method). The basic idea of the Moment Method is as follows: The unknown quantity $(f)$ is expanded in terms of a set of linearly independent known functions, $f_{n}$ (referred to as basis or expansion functions), or in other words it's expanded by following finite series:

$$
f \approx \sum_{n=1}^{N} \alpha_{n} f_{n}
$$

where $\alpha_{n}$ are unknown expansion coefficients yet to be determined. The expansion functions should be chosen, usually based on experience, so that reasonable approximation of $\mathrm{f}$ is obtained with a small number of terms, N [15]. Substituting this into linear-operator equation and taking into consideration the linearity of the operator, we get

$$
\sum_{n=1}^{N} \alpha_{n} L\left(f_{n}\right) \approx g
$$

The next step in Moment Method is to determine unknown coefficients. It's done by multiplying both sides of equation (2) by a known, properly selected function (weighting) function, $w_{m}$, and the results integrated over a spatial region. This integration is special, but very frequent case of an inner product of two functions, $f$ and $g$, which is denoted by $\langle f, g\rangle$ and it satisfies all conditions of the inner product of scalars. Now we have following equation

$$
\sum_{n=1}^{N} \alpha_{n}<w_{m}, L\left(f_{n}\right)>\approx<w_{m}, g>
$$

where, $m=1, \ldots, N$. Equation (3) represents a system of $\mathrm{N}$ ordinary linear equations with $\mathrm{N}$ unknowns and it can be solved using various techniques [15]. In Fig. 4, equivalent circuit of an inset fed microstrip patch antenna is shown.

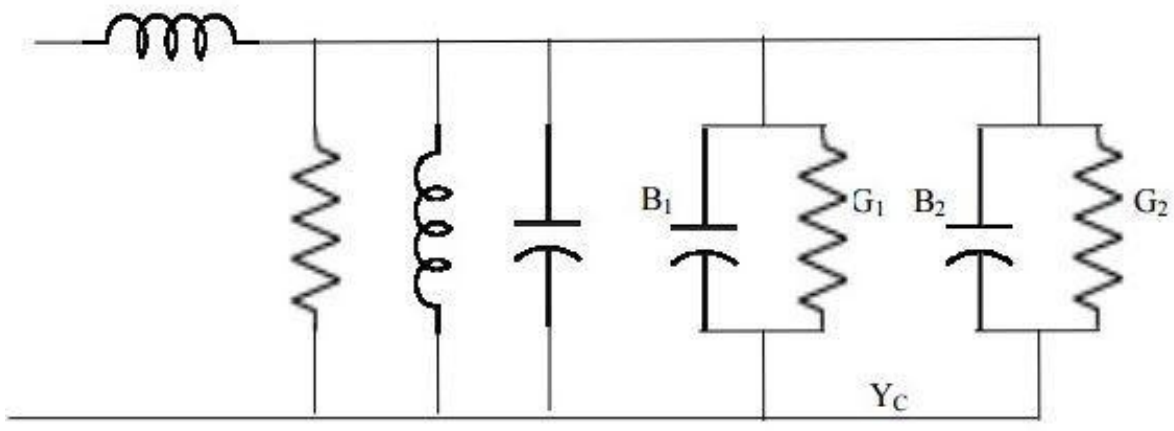

Figure 4. Equivalent Circuit of Inset fed Microstrip Patch Antenna [16]

Power density of an antenna carried far away from the antenna is defined as

$$
P_{d}=\frac{1}{2} \operatorname{Re}\left(E \times H^{\prime}\right)=\frac{E^{2}}{2 \eta_{0}}
$$

where, $\eta_{0}=\sqrt{\frac{\mu_{0}}{\epsilon_{0}}}=120 \pi$. 
The most important parameter of an antenna is radiation pattern. For a transmit antenna; this is a plot of Power density (Pd or field strength $\mathrm{E}$ ) radiated by the antenna in different angular directions. A plot for the vertical and horizontal planes were named as "polar pattern diagrams". The same pattern applies for the receiving antenna [5]. This can be seen in Fig. 5.

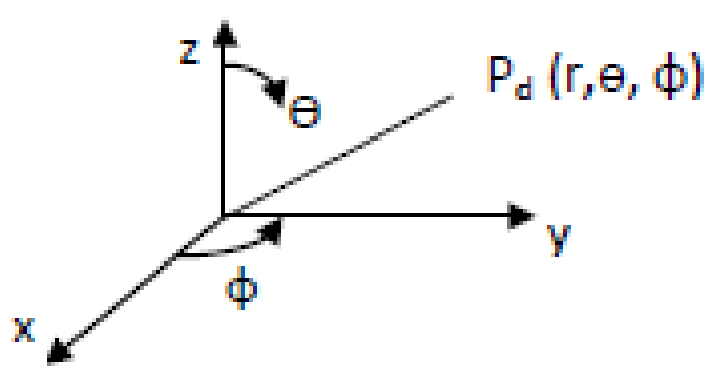

Figure 5. Radiation Pattern Definition

Gain of antenna is also one of the important parameters. The term Antenna Gain describes how much power is transmitted in the direction of peak radiation to that of an isotropic source [17]. It is the ratio of the radiation intensity in a given direction to the radiation intensity that would be obtained if the power accepted by the antenna were radiated isotopically (in all directions). In other words, it takes the directivity of the antenna along with its effectiveness. It is expressed in decibels $(\mathrm{dB})$

$$
\begin{gathered}
G=\frac{\text { Power radiated by the antenna }}{\text { Power recieved by the reference antenna }} \\
G=\eta \mathrm{D} \quad(6) \\
\eta=\text { efficiency }=\frac{P_{\text {rad }}}{P_{\text {in }}}<1
\end{gathered}
$$

In practice, some portion of input power is lost, so efficiency becomes

$$
\eta=1-\frac{P_{\text {loss }}}{P_{\text {in }}}
$$

A useful parameter calculating the receive power of an antenna is the effective area or effective aperture [18].

$$
A=\frac{\lambda^{2}}{4 \pi} G
$$

Power received by an antenna can be associated with a collecting area [5].

$$
A=\frac{P_{r e c}}{P_{d}}
$$

\section{Conclusion}

In this work, a slitted inset fed butterfly-shaped microstrip patch antenna is designed and simulated. Simulation was performed in a 3D planar high-frequency electromagnetic software called Sonnet. Design was 
modified by changing the geometry of a square inset fed antenna, by adding indentations to the sides and top part of the design, increasing and decreasing the length of the inset, until satisfactory results were obtained. The performance of the antenna is observed based on its S11 parameter (return loss) and the gain. S11 at $26.35 \mathrm{GHz}$ gets $-34.48 \mathrm{~dB}$ return loss, while gain is $7.37 \mathrm{~dB}$. The research methods included operational requirement analysis, parameter sensitivity analysis, optimization analysis and software simulation.

\section{References}

[1] 5G spectrum access at $26 \mathrm{GHz}$ and update on bands above $30 \mathrm{GHz}$. www.ofcom.org.uk

[2] M. A. M. Omar, A. M. E. Zayid, E. H. A. Samra, "Design and Analysis of Millimeter Wave Microstrip Patch Antenna for 5 G Applications", IEEE Circuits and Systems Conference, March, 2019.

[3] R. Mishra, R. G. Mishra, R. K. Chaurasia, A. K. Shrivastava, "Design and Analysis of Microstrip Patch Antenna for Wireless Communication", International Journal of Innovative Technology and Exploring Engineering, vol. 8, no. 7, pp. 663-666, 2019

[4] H. Werfelli, K. Tayari, M. Chaoui, M. Lahiani, H. Ghariani, "Design of Rectangular Microstrip Patch Antenna", 2nd International Conference on Advanced Technologies for Signal and Image Processing, March, 2016

[5] Ş. T Imeci, "Design and manufacture of Patch Antennas", Sarajevo, BiH: International University of Sarajevo, 2017

[6] L. Sun, M. He, J. Hu, Y. Zhu, H. Chen, "A Butterfly-Shaped Wideband Microstrip Patch Antenna for Wireless Communication”, International Journal of Antennas and Propagation, 2015

[7] O. Darboe, D. B. O. Konditi, F. Manene, "A 28 GHz Rectangular Microstrip Patch Antenna for 5G Applications", International Journal of Engineering Research and Technology, 2019

[8] Sonnet Suites, ver. 17.52. Syracuse, New York

[9] G. Zhao, F.-S. Zhang, Y. Song, Zi-Bin Weng and Y.-C. Jiao, "Compact ring monopole antenna with double meander lines for 2.4/5 GHz dual-band operation", Progress in Electromagnetics Research, PIER 72, pp. 187-194, 2007.

[10] K. Siakavara, Methods to Design Microstrip Antennas for Modern Applications, 2011.

[11] K. F. Lee, K. M. Luk, H. W. Lai, Microstrip Patch Antennas, 2nd edition, World Scientific, 2017.

[12] N. Irfan, M. C. E. Yagoub, K. Hettak, "Design of a Microstrip-Line-Fed Inset Patch Antenna for RFID Applications", IACSIT International Journal of Engineering and Technology, vol. 4, no. 5, 2012.

[13] L. C. Paul, S. Hosain, S. Sarker, M. H. Prio, M. Morshed, A. K. Sarkar, "The Effect of Changing Substrate Material and Performance of Inset Feed Microstrip Patch Antenna", American Journal of Networks and Communications, vol. 4, no. 5, pp. 54-58, 2015.

[14] N. Ismail, T. S. Gunawan, S. Kartika, T. Praludi, E. A. Z. Hamidi, "Design of Microstrip Hairpin Bandpass Filter for $2.9 \mathrm{GHz}$ - 3.1 GHz S-band Radar with Defected Ground Structure," Malaysian Journal of Fundamental and Applied Sciences, vol. 14, 2018.

[15] R. A. Djordjevic, M. B. Kolundzija, "Method of Moments Applied to Antennas", School of Electrical Engineering, University of Belgrade, November 2000.

[16] M. Matin, A. Sayeed, "A design rule for inset-fed rectangular microstrip patch antenna", WSEAS Transactions on Communications, vol. 9, no. 1, pp. 63-72, 2010.

[17] Antenna Gain, last accessed on $9^{\text {th }}$ June, 2020. Available:http://www.antennatheory.com/basics/gain.php,

[18] Effective Area (Effective Aperture), last accessed on $9^{\text {th }}$ June, 2020. Available: http://www.antennatheory.com/basics/aperture.php 